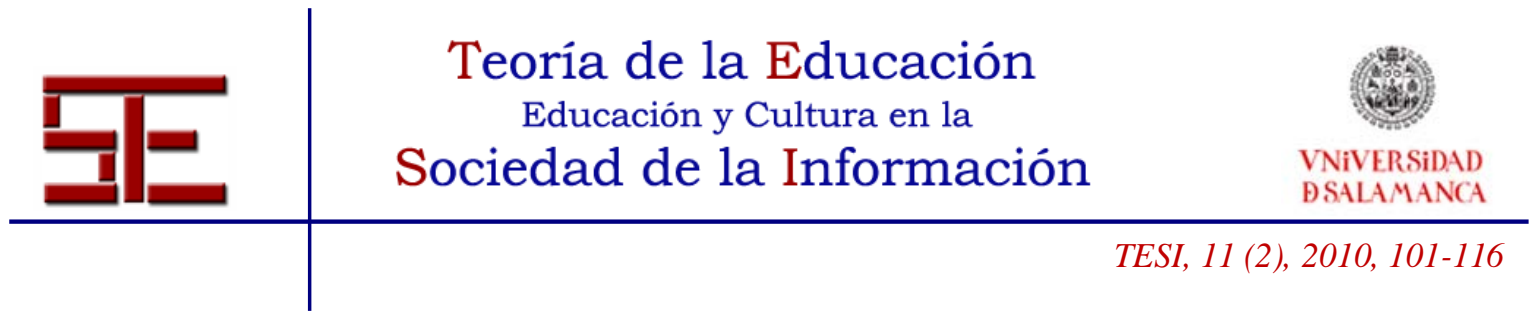

\title{
AVANCES EN EL DESARROLLO DE INTERFACES DE USUARIO DE PROGRAMAS DOCENTES: IMPORTANCIA DE SU DISEÑO PARA LA EFICACIA Y OPTIMIZACIÓN DEL APRENDIZAJE
}

Resumen:

Presentamos una valoración y análisis de diferentes interfaces de usuario de desarrollos informáticos, de carácter docente, generados por nosotros, con el fin de elaborar unos diseños que permitan una mayor optimización del proceso enseñanza-aprendizaje a través de estos medios tecnológicos. Incorporamos en ellos distintos elementos ilustrativos como iconos, imágenes, etc. que facilitan la rápida interacción del usuario con el procedimiento informático.

Para evaluar la eficacia y potencialidad de nuestros desarrollos informáticos, de formación médica, llevamos a cabo una encuesta a diferentes usuarios, basada en la escala de Likert, con el fin de conocer el grado de satisfacción del procedimiento informático.

Los resultados obtenidos manifiestan una excelente aceptación de nuestros diseños de interfaces, tanto en su eficacia en el funcionamiento de los diferentes controles de navegación, como en la disposición y distribución de los mismos, lo que contribuye a un buen equilibrio visual de la aplicación informática.

Palabras clave: Programas docentes informatizados, Interfaces de usuario, aprendizaje

Juan Antonio Juanes Méndez, Alberto Prats Galindo y Juan

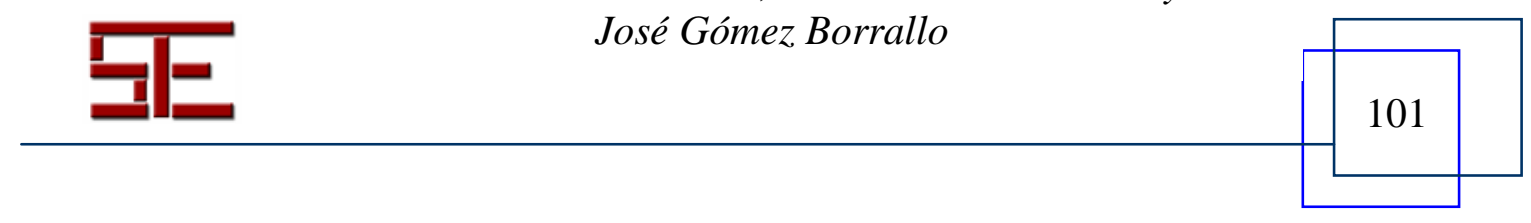




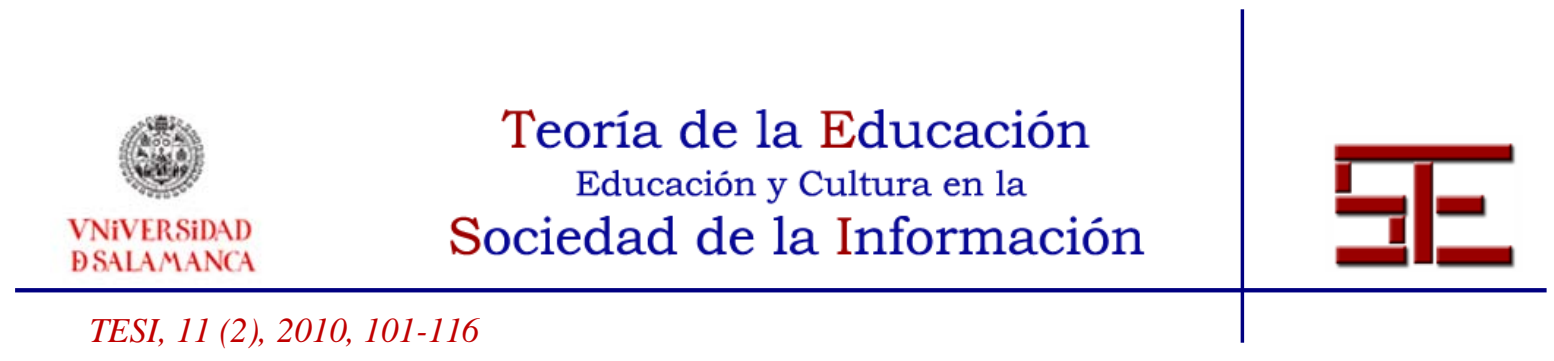

ADVANCES IN THE DEVELOPMENT OF USER INTERFACES OF TEACHING PTOGRAMS: THE IMPORTANCE OF DESIGN FOR THE EFFICIENCY AND OPTIMIZATION OF LEARNING

\begin{abstract}
:
We report an evaluation and analysis of different user interfaces of IT applications, for teaching purposes, generated by Us with a view to developing designs that will allow better optimization of the teaching-learning process through these technological means. In them, we have incorporated different illustrative elements, such as icons, images, etc... that facilitate rapid interaction between the user and the informatics procedure.

To evaluate the efficiency and potential of our developments, aimed at training in the field of medicine, we sent out a Likert-based questionnaire to different users to gauge the degree of satisfaction with the informatics procedure.

The results obtained reveal the excellent acceptance of our interface designs, both as regards their efficiency in the functioning of the different navigation controls and their distribution, which contributes to a good visual balance of the informatics application.
\end{abstract}

Key words: Computerized teaching programs, User interfaces, Learning

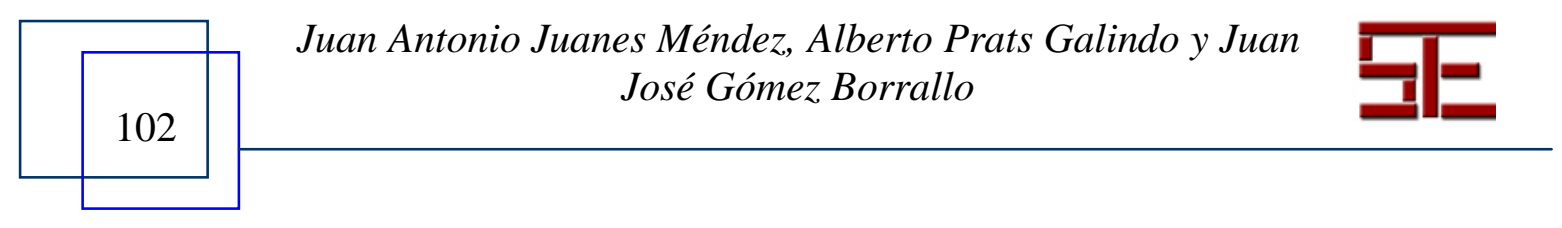




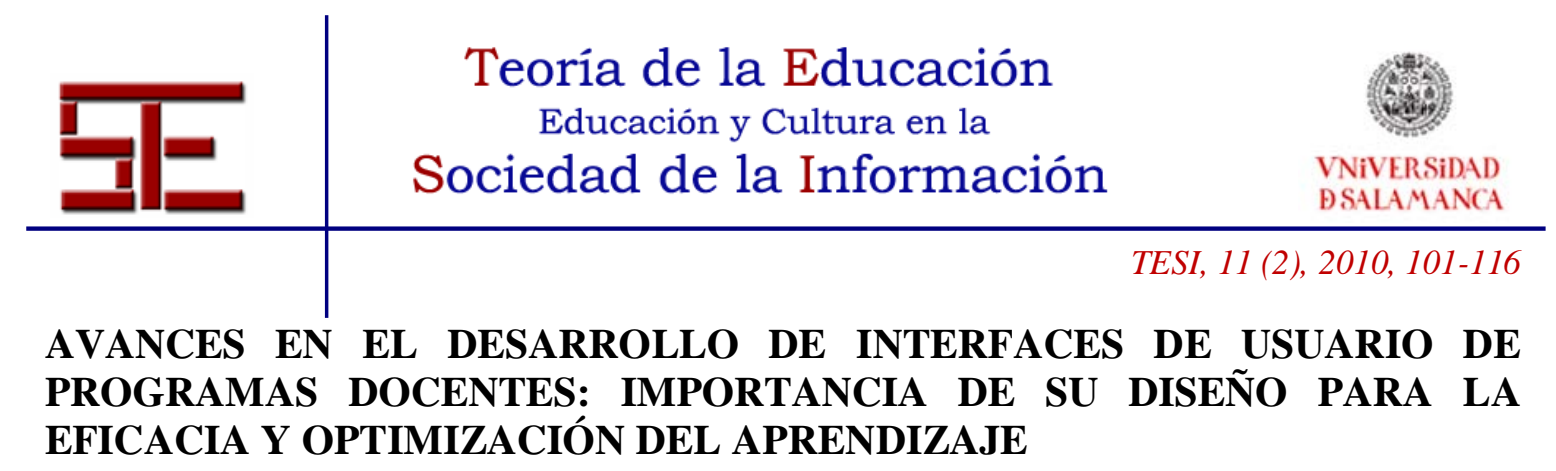

Fecha de recepción: 03/11/2009; fecha de aceptación: 27/05/2010; fecha de publicación: 05/07/2010

Juan Antonio Juanes Méndez

jajm@usal.es

Universidad de Salamanca

Alberto Prats Galindo

aprats@ub.edu

Universidad de Barcelona

Juan José Gómez Borrallo

juanjose@abadianet.com

Desarrollos informáticos Abadía. Madrid

\section{1.- INTRODUCCIÓN}

La tecnología informática, aplicada a la formación en ciencias de la salud, ha sufrido muchos cambios a lo largo del tiempo, paralelo a la evolución tecnológica de nuestra sociedad. En el mismo sentido, los programas docentes informatizados han sufrido transformaciones notables en los últimos años. La propia investigación científica como base del progreso humano, ha llevado a muchos docentes y científicos a pensar que ésta podría propiciar una nueva era de la práctica educativa y formativa, en el ámbito de la las ciencias de la salud.

Esta evolución ha venido dada tanto por elementos de soporte técnico, es decir el hardware empleado; así como por los contenidos transmitidos a través de programas informáticos, es decir, el software. La unión de ambos ha supuestos cambios metodológicos en la transmisión del conocimiento, y por tanto cambios en los sistemas de enseñanza-aprendizaje.

Es a partir de la década de los años 70, cuando el desarrollo de la informática consolida la utilización de los ordenadores con fines educativos, concretada inicialmente en aplicaciones como los programas de Enseñanza Asistida por Ordenador (EAO), es decir, programas informáticos basados en el modelo asociacionista de aprendizaje que recuperan conceptos de la enseñanza programada y de las máquinas de enseñar. En la actualidad, la difusión de las Tecnologías de la Información y Comunicación (TIC), en todos los ámbitos y estratos sociales, ha multiplicado su presencia en los centros docentes universitarios de nuestro país.

Pero aplicar tecnologías informáticas para la formación, supone tener unos buenos conocimientos técnicos y pedagógicos para desarrollar aplicaciones docentes que

Juan Antonio Juanes Méndez, Alberto Prats Galindo y Juan

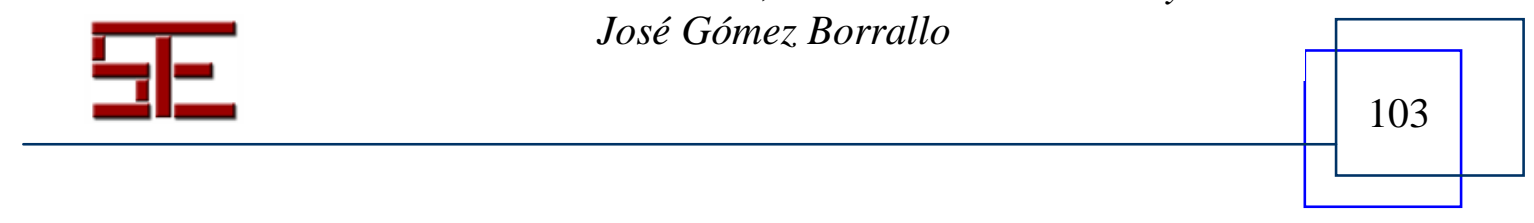




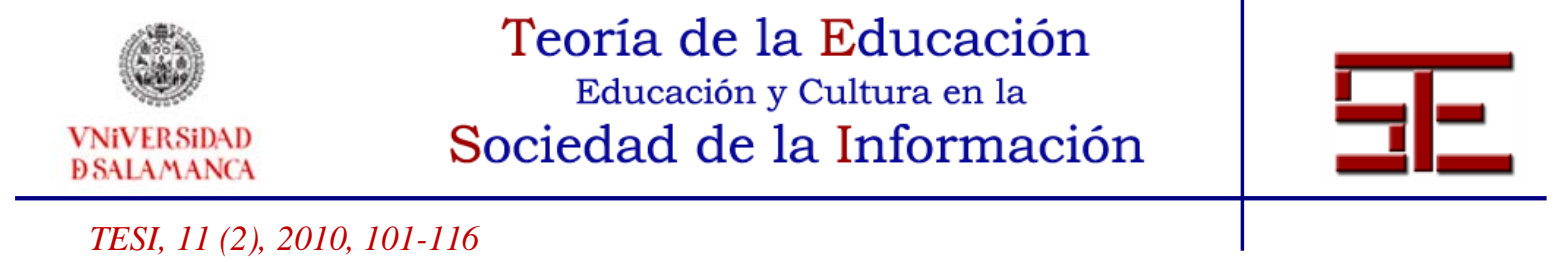

permitan lograr conseguir una optimización del aprendizaje de nuestros alumnos. Por eso, aplicar tecnologías en la formación no se basa solamente en el dominio instrumental de unos equipamientos informáticos, sino en la capacidad para diseñar desarrollos informáticos docentes de formación en ciencias de la salud, con el objeto de alcanzar los objetivos que nos hubiéramos marcado, donde se fueran a aplicar. Por tanto, como se señalara en el "Council for Educational Technology" en 1977, "la Tecnología Educativa es la aplicación del saber, sistemas y técnicas, para mejorar el aprendizaje humano".

La aplicación de tecnologías informáticas en la formación, debe contribuir a ampliar los márgenes de acción, decisión e intercomunicación entre profesores y alumnos, permitiendo además, el acceso a los nuevos medios de explorar, representar y tratar el conocimiento. La evolución más evidente ha sido en el diseño de nuevos interfaces de usuario que faciliten el entorno de comunicación o interactividad entre hombre-máquina

\section{2.- CONSIDERACIONES SOBRE LOS INTERFACES DE USUARIO.}

Entendemos por interface la conversión computacional, es decir, la forma de poder comunicarse entre el ordenador, mediante un desarrollo informático, y el usuario. Para ello se emplean gráficos visuales como iconos, símbolos, texto, etc... que faciliten esa interacción entre el programa y el usuario. Podemos señalar que un interface constituye la puerta de entrada a interactuar con un desarrollo informático, siendo los diferentes iconos o símbolos, la llave que permite franquear esa puerta.

El desarrollo de los interfaces de usuario ha enriquecido, sin duda, las interacciones con el receptor, siendo las aplicaciones de carácter multimedia, las que han generado una mayor diversidad de opciones de interfaces. Los iconos siguen siendo siguen siendo un elemento fundamental para la navegación por el programa informático. Conocerlos mejor estos iconos permitirá profundizar mejor en las relaciones interactivas del usuario con el ordenador.

El avance tecnológico que se ha incrementado en los últimos años, esta permitiéndonos manejar herramientas de autor, que facilitan la elaboración de interfaces para programas docentes informatizados, de una forma sencilla y rápida, para que puedan ser empleados, con fines educativos, como instrumentos didácticos complementarios en el proceso de enseñanza-aprendizaje.

En el diseño y elaboración de un interface de usuario de un programa informatizado, se deberá tener en consideración dos aspectos fundamentales: por un lado, el pedagógico y por otro, el propio diseño. Desde el punto de vista pedagógico se deberá tener en cuenta el contenido a transmitir con la aplicación informática, es decir, habrá que considerar muy bien, cuales son los conceptos, ideas y mensaje principal a comunicar al usuario del procedimiento informático docente. En este sentido, será importante analizar bien las formas de presentación de los contenidos didácticos, con sus descripciones y

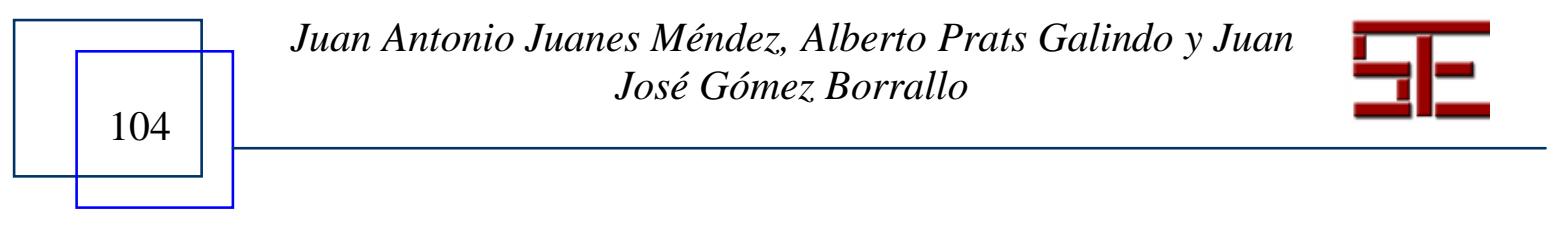




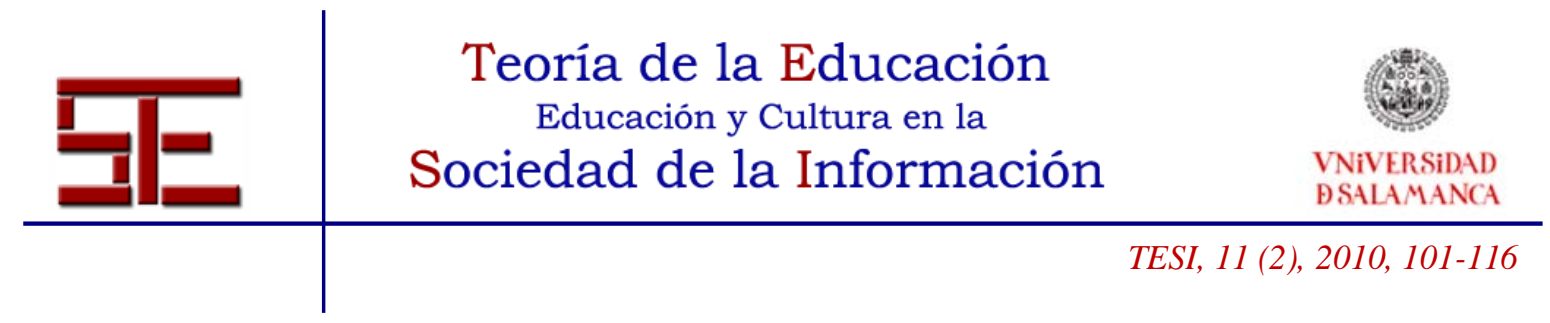

conceptos adecuados y oportunos. En cuanto al punto de vista del diseño de la aplicación informática, tendremos que valorar la forma de presentación de los contenidos docentes y su composición y distribución en la pantalla del ordenador. Este diseño siempre buscará el máximo impacto de comunicación entre el emisor y el receptor, empleando para ello, texto, imágenes, iconos, etc..; es decir, el diseño del interface mirará las necesidades comunicativas del usuario, utilizando diferentes formas de representación visual. El objetivo final con el diseño de la aplicación informática elaborado, es contribuir y facilitar, de forma eficaz, el aprendizaje.

En el diseño de un interface de usuario de programas docentes, es importante tener en consideración aspectos como la composición, la estética y sobre todo la funcionalidad.

La forma como distribuyamos los elementos en la pantalla del ordenador, es decir, su posición y disposición, influirá en la respuesta del usuario para mantener una buena atención sobre el desarrollo informático, que despierte el interés por el contenido didáctico.

La estética de un programa docente informatizado también es de gran importancia en el diseño de un interface, ya que a simple vista, esto puede provocar una reacción en el usuario de atracción o de rechazo de la aplicación informática. Un diseño atractivo, genera sobre el usuario una fuerza mayor para el aprendizaje, estimulándolo a permanecer más tiempo sobre los contenidos del programa docente. Por otro lado, un diseño estéticamente atractivo, permitirá al usuario retener o memorizar mejor los conceptos transmitidos con la aplicación informática.

Finalmente, una buena funcionalidad del interface hará también que el usuario se sienta atraído, al comprobar que apenas requiere esfuerzo para utilizar la aplicación informática, permitiéndole explorarla, de forma sencilla, y sin un tiempo prolongado para su manejo.

Mordecki, en su artículo titulado "Interfaces e Intuición” (2007), describe un procedimiento para medir la eficacia de los componentes de un interface de usuario, según unos niveles de complejidad. En el nivel más elemental y básico de interacción se requiere un esfuerzo escaso o nulo para la comunicación hombre-máquina, ya que emplea patrones de referencia previamente experimentados en otras aplicaciones de uso cotidiano y común, lo que le permite manejarse de forma óptima dentro de la aplicación informática. Un segundo nivel, mas elevado, requiere un mayor esfuerzo, en donde el usuario debe leer y entender aquello que se le indica, a través de lo que se ha dado en denominar lectura autoexplicativa. Finalmente, el nivel más superior, requiere entender conceptos, ideas y relaciones que no figuran en la pantalla, lo que obliga al usuario a pensar permanentemente en su interacción.

Los interfaces intuitivos tienen en común el comprender las cosas de forma instantánea, sin necesidad de razonamiento. En este tipo de interfaces, los iconos juegan un papel

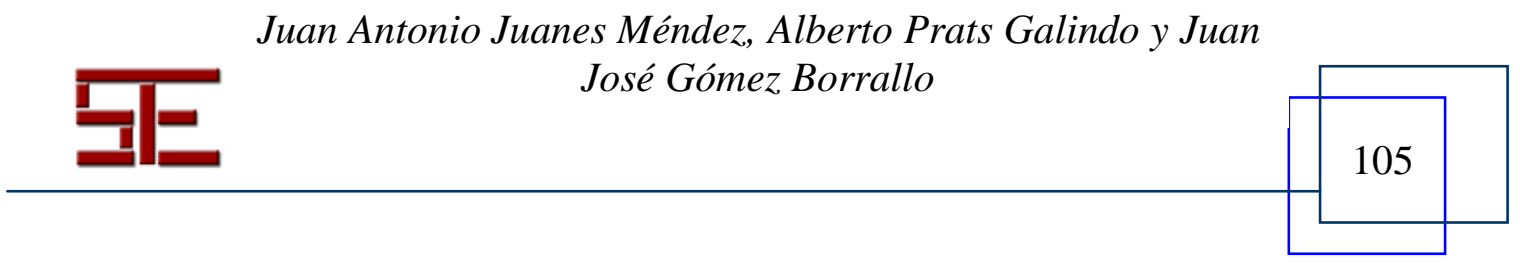




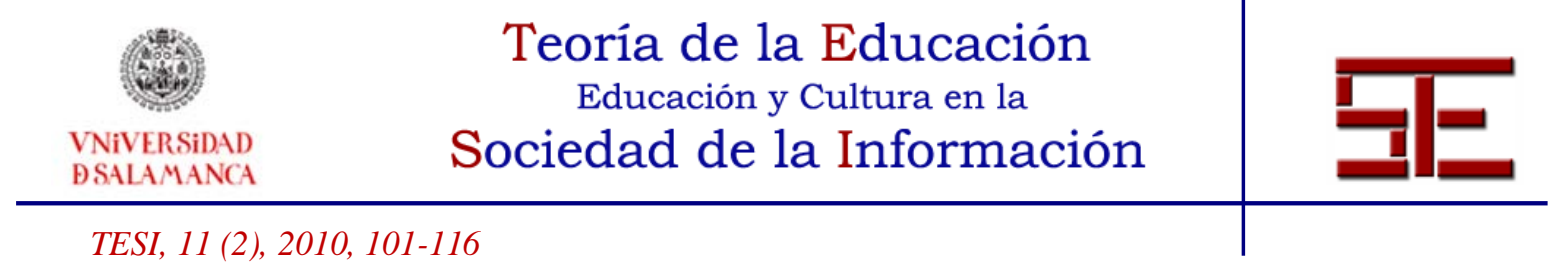

importante, sobre todo si se les añade un tooltip, es decir, una frase corta que aparece en un rectángulo cuando nos ponemos sobre el icono.

Por tanto, los iconos dentro de un programa docente informatizado, no son meros elementos decorativos, sino parte esencial de los mecanismos de interacción de cualquier interface de usuario.

Los iconos sustituyen a una buena cantidad de significados que, si fuesen representados con texto, ocuparían bastante espacio dentro de la pantalla del ordenador; por ello, una de las principales ventajas de la utilización de estos recursos es que nos permiten representar más unidades de significado, en un menor espacio, lo que se consigue obtener una buena funcionalidad en el mínimo espacio y con la máxima rapidez de acción. El significado de la mayoría de iconos debe ser aprendido, siendo esto un problema menor cuando existe una buena motivación por el aprendizaje y por el atractivo en el diseño de la aplicación informática. En ocasiones, el icono es importante por el aspecto visual que le aporta al desarrollo informático mas que por su operatividad; sobe todo cuando lo que se desea es que el usuario investigue y descubra por si mismo el funcionamiento del interface. Los iconos son muy válidos en aplicaciones donde el usuario tiene una motivación grande para el aprendizaje, lo que le lleva a un uso repetitivo del programa informático y por tanto a un mejor acercamiento a su comprensión. No obstante, los iconos también tienen algunas pequeñas limitaciones, ya que no se reconocen tan rápidamente como los textos. No podemos olvidar que el lenguaje icónico está sujeto a la interpretación individual y subjetiva de cada usuario a partir de su experiencia en el manejo y manipulación de estas aplicaciones informáticas. No siempre los iconos son totalmente claros e inequívocos y por tanto existe el riesgo de malinterpretarlos y malentenderlos. En las primeras experiencias en el manejo de desarrollos informáticos con iconos interactivos requieren mas tiempo para ser identificados que con los textos; sien embargo, con el tiempo de utilización y experimentación se consigue una mayor rapidez y se genera un ambiente mas estético y atractivo para el usuario; por ello, es muy importante la creación de varios diseños o prototipos para cada icono, así como la realización de test con usuarios reales que nos informen de la utilidad y validez de los iconos y símbolos introducidos en una aplicación informática docente; esto nos permitirá extraer conclusiones valiosas sobre el diseño empleado.

\section{3.- DISEÑO Y EVALUACIÓN DE INTERFACES DE USUARIOS PROPIOS.}

Desde hace varios años nuestro grupo viene trabajando en el desarrollo de programas docentes informatizados, con el único fin de mejorar la calidad de la enseñanza, aplicando las tecnologías más innovadoras. Fruto de este trabajo colectivo ha sido el desarrollo de múltiples procedimientos informáticos aplicados al aprendizaje de la Anatomía Humana, mediante la reconstrucción tridimensional de estructuras corporales,

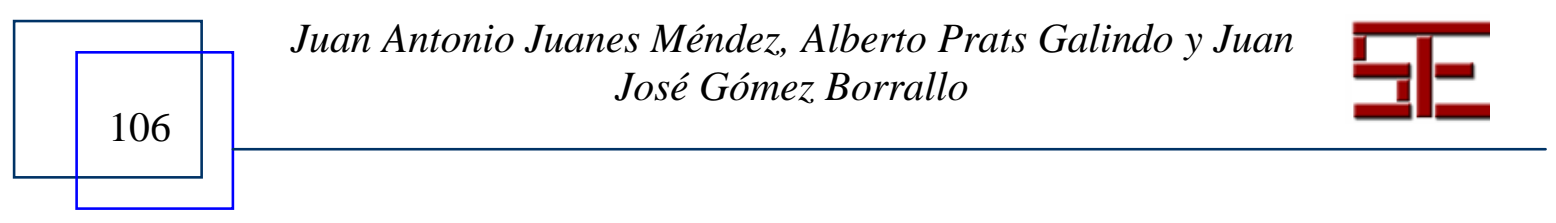




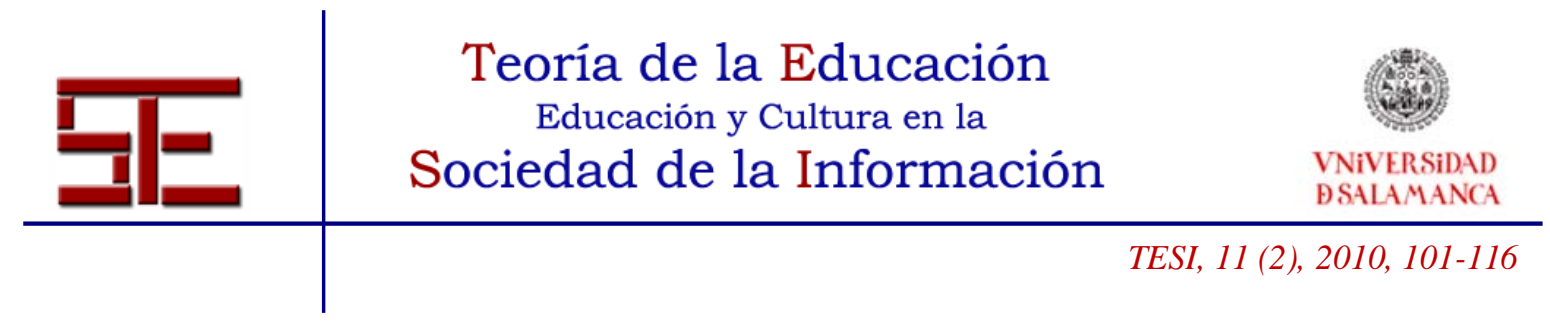

desde imágenes radiológicas seccionales, para su visualización en cualquier posición espacial (Espuña y cols, 2006; Juanes y cols, 2001; 2006). Estos desarrollos informáticos constituyen verdaderos atlas anatómicos dinámicos, siendo el usuario el que decide cómo quiere visualizar una estructura anatómica.

Los interfaces empleados por nosotros han buscado siempre facilitar la navegación por el programa, intentando ser lo más intuitivos posibles. Están elaborados con Visual C, siendo éste una forma rápida y cómoda para crear interfaces para plataformas Windows. Esta herramienta informática permite agregar los controles a la superficie del diseño, establecer las propiedades iniciales de los controles, escribir los controladores para los eventos especificados, etc.

Presentamos, mediante pantallas, algunos ejemplos de interfaces de programas informáticos docentes que hemos desarrollado: un visor anatómico para el estudio de la morfología de la mano en tres dimensiones, generado a partir de secciones seriadas de Tomografía Computarizada (Figs. 1 a 4), y alguna pantalla de un procedimiento informático para el estudio de la anatomía encefálica, en tres dimensiones, con imágenes de Resonancias Magnética, en los tres planos del espacio (sagital, axial y coronal). (Figs 5 y 6 ).

Hemos llevado a cabo una encuesta de satisfacción a diferentes usuarios $(n=85)$ del ámbito sanitario (Gráfica 1), para valorar la operatividad de nuestras aplicaciones informáticas docentes, con el fin de mejorar y optimizar el aprendizaje de los usuarios. La distribución de usuarios fue la siguiente: 40 estudiantes de diferentes titulaciones de ciencias de la salud, diez por cada titulación (terapia ocupacional, enfermería, fisioterapia, medicina); 20 médicos internos residentes (MIR) (10 de traumatología y 10 de oftalmología), 10 especialistas en las mismas áreas que los residentes (cinco por cada área) y 15 médicos de atención primaria de diferentes centros de salud.

Empleamos una encuesta utilizando la escala de Likert, una de las más ampliamente utilizadas en investigación (Likert, 1932). Incluimos unos ítems, con enunciados afirmativos o negativos sobre el tema o actitud que se pretenda medir. Se solicita a los sujetos encuestados que expresen su acuerdo o desacuerdo frente a cada ítem mediante una escala que oscila entre uno y cinco; siendo uno para indicar un total desacuerdo y cinco para señalar que está totalmente de acuerdo. La unidad de análisis que responde a la escala marcará su grado de aceptación o rechazo hacia la proposición expresada en el ítem.

Encontramos un alto grado de satisfacción con el procedimiento empleado. Las medias de los resultados obtenidos se muestran en las gráficas 2 a 6 , y en la tabla 1, donde se refleja una valoración muy positiva en cada uno de los ítems formulados.

Juan Antonio Juanes Méndez, Alberto Prats Galindo y Juan

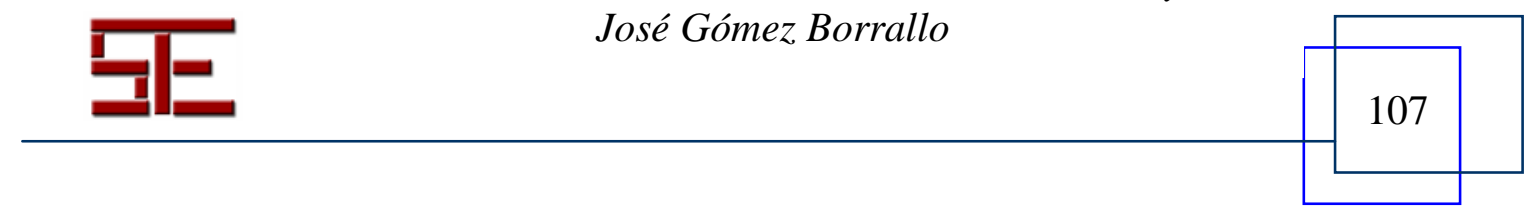




Teoria de la Educación
Educación y Cultura en la
$\begin{gathered}\text { VNiVERSIDAD } \\ \text { DSALAMANCA }\end{gathered}$

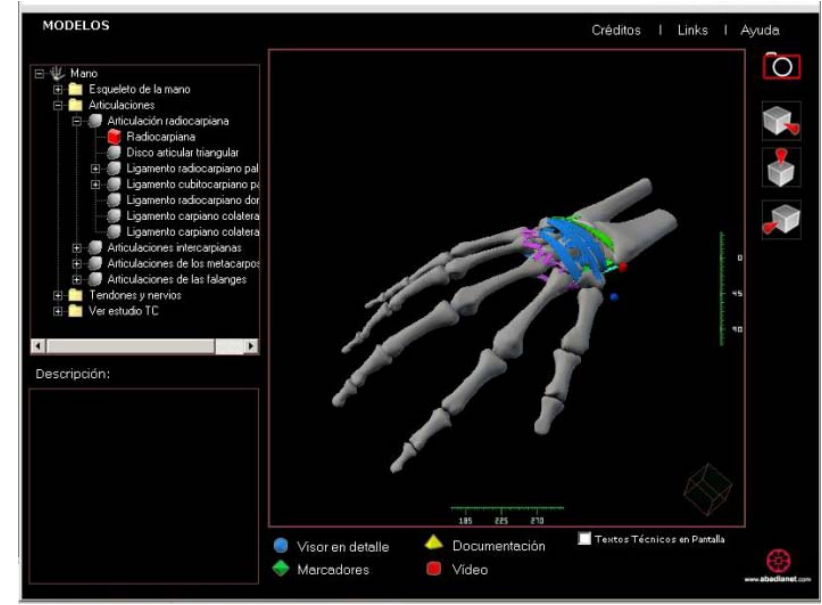

Figura 1. Visualización del interfaz de usuario de un programa docente informatizado para el estudio de la Anatomia de la mano. L aparte central, más amplia, corresponde al visor de estructuras anatómicas en $3 D$, con el que se puede interactuar por medio del ratón tanto para cambiar el punto de vista. A la izquierda está presente el árbol con los modelos anatómicos que intervienen en el visor, ordenados jerárquicamente. En la parte derecha se encuentran las opciones de visualización, mediante iconos representativos, que permiten cambiar el punto de vista o poder obtener una foto del contenido que estemos visualizando.

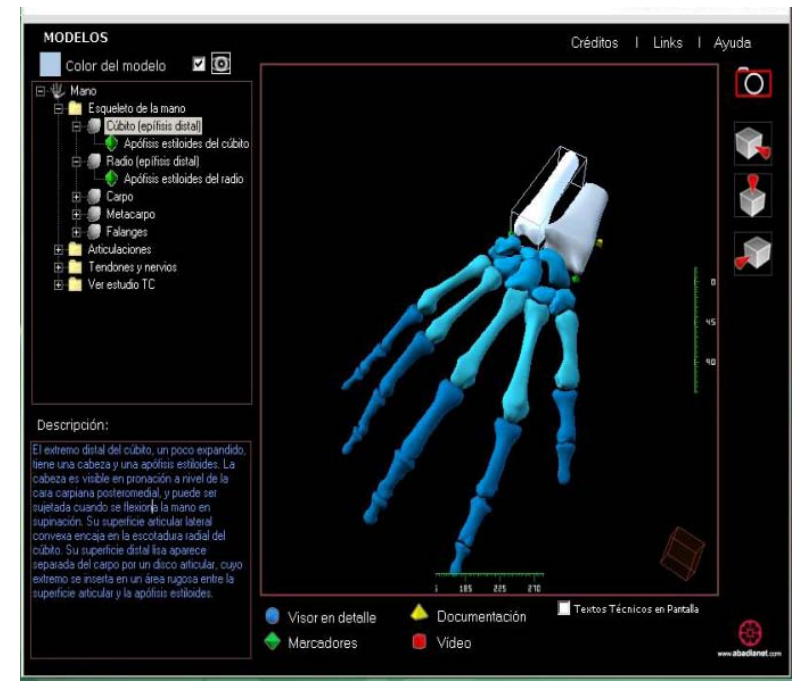

Figura 2. En el visor 3D y en el árbol de modelos se encuentran enlaces a los distintos elementos que completan al visor 3D, y que se mostrarán en forma de ventanas flotantes: Vídeo: abre una ventana con una animación multimedia. Visor en detalle: abre una ventana con un visor en detalle, una versión reducida del visor anatómico para ver de manera más completa ciertos elementos. Documentación: muestra una ventana con documentación asociada al elemento sobre el que se encuentran. Esta documentación incluye tanto imágenes como una breve descripción de las mismas.

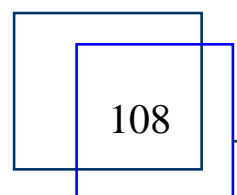

Juan Antonio Juanes Méndez, Alberto Prats Galindo y Juan José Gómez Borrallo

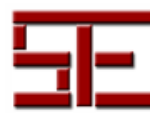




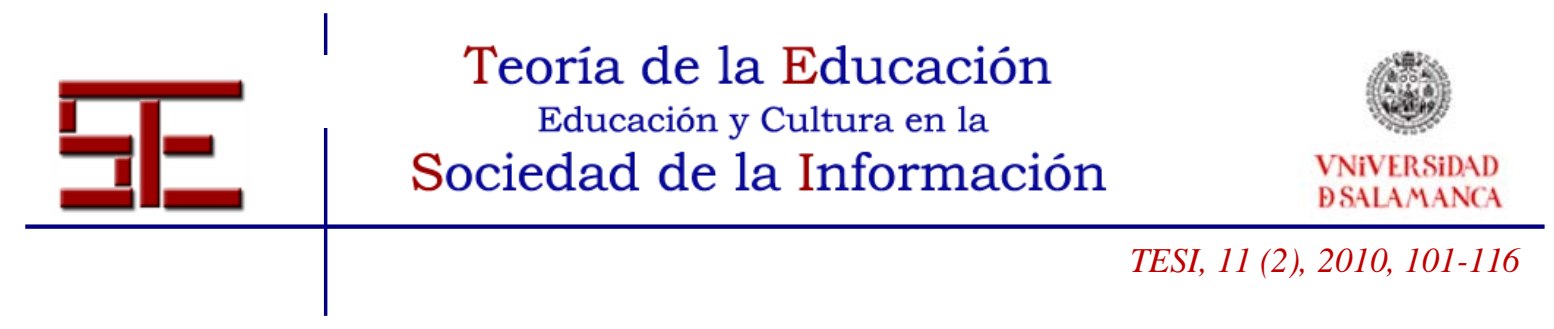

Figura 3. Visualización de una ventana con animación multimedia donde se describe el funcionamiento y algunas características de las articulaciones de la mano. En la parte inferior se muestran los distintos controles de reproducción que permiten reanudar, pausar y detener la reproducción respectivamente. Junto a estos aparecen opciones de sonido, que nos permiten silenciar la locución, y aumentar y reducir el volumen de la misma. Bajo estos se encuentra una línea de reproducción para poder desplazarnos a lo largo de la misma para buscar partes específicas de la animación.
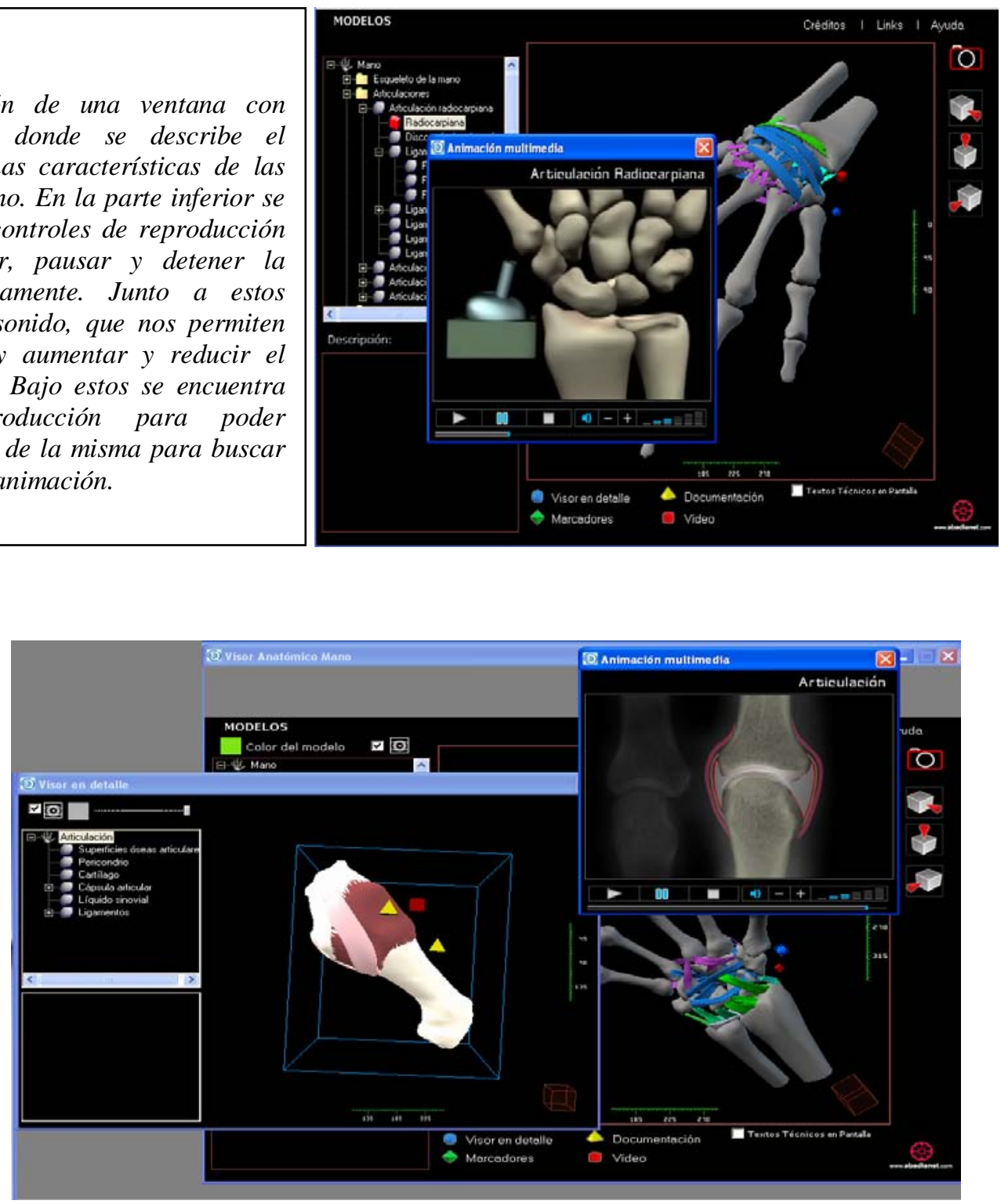

Figura 4. Visualización de diferentes pantallas flotantes de acceso a información adicional y complementaria. El visor en detalle nos permite ver las particularidades de ciertos modelos específicos. Sus funcionalidades incluyen tanto las del visor estándar (rotaciones, traslaciones, zoom y selección) como las del árbol de modelos (relación jerárquica, visibilidad y colores de los modelos 3D). Mientras esté activo el visor en detalle, la ventana principal permanecerá deshabilitada, pudiendo regresar a él al cerrar el visor.

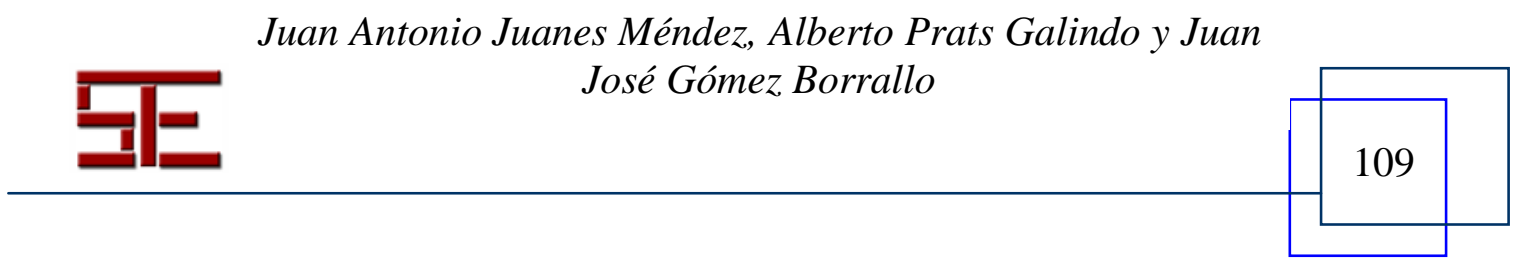




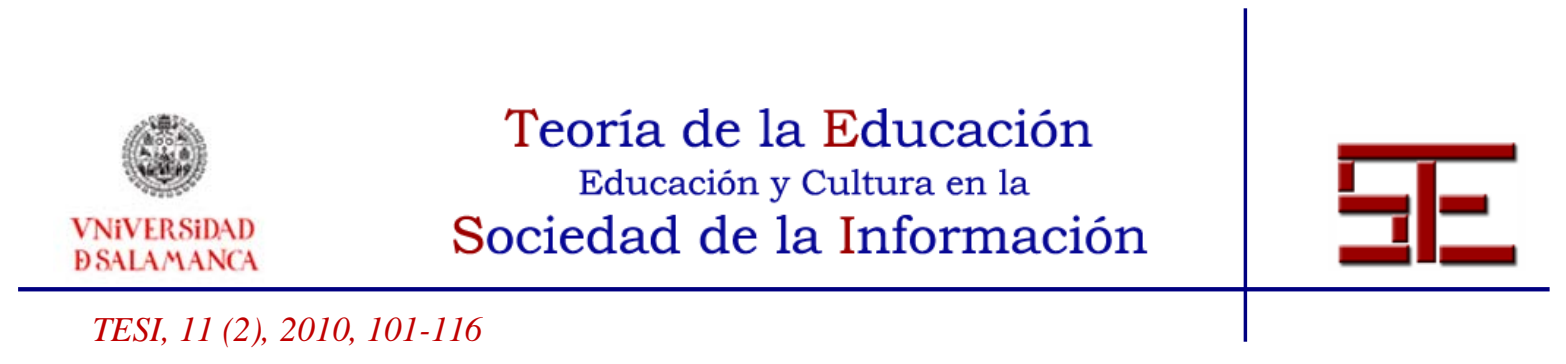

Encuesta de Satisfacción

\section{Presentación:}

Con objeto de evaluar la calidad y diseño de nuestros programas docentes informáticos $y$, mejorar el desarrollo de nuevos procedimientos, le agradeceríamos que valorase su grado de satisfacción, tras su manejo, respecto de las siguientes afirmaciones.

Gracias por tu colaboración.

Usuario:
\begin{tabular}{lll}
\hline Estudiante. $\square$ Residente MIR $\square$ Especialista $\square$ Medicina Atención Primaria $\square$ otros \\
VALORACIONES: & $\begin{array}{l}\text { Totalmente } \\
\text { en desacuerdo (1) }\end{array}$ & Totalmente \\
& de acuerdo (5)
\end{tabular}

\begin{tabular}{|c|c|c|c|c|c|c|c|}
\hline \multirow{3}{*}{ 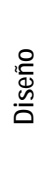 } & 1 & La distribución y composición de la pantalla es sencilla y ordenada & $\square$ & $\square$ & $\square$ & $\square$ & $\square$ \\
\hline & 2 & La apariencia de los controles de navegación es sencilla & $\square$ & $\square$ & $\square$ & $\square$ & $\square$ \\
\hline & 3 & $\begin{array}{l}\text { La correspondencia entre la representación visual y el concepto } \\
\text { representado resulta sencillo de interpretar }\end{array}$ & $\square$ & $\square$ & $\square$ & $\square$ & $\square$ \\
\hline
\end{tabular}

\begin{tabular}{|c|c|c|c|c|c|c|c|}
\hline \multirow{7}{*}{ 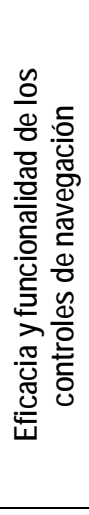 } & 4 & $\begin{array}{l}\text { La disposición de los elementos del interfaz facilita su rápida } \\
\text { identificación }\end{array}$ & $\square$ & $\square$ & $\square$ & $\square$ & $\square$ \\
\hline & 5 & $\begin{array}{l}\text { La disposición de los controles de navegación favorece la comodidad en } \\
\text { su manejo }\end{array}$ & $\square$ & $\square$ & $\square$ & $\square$ & $\square$ \\
\hline & 6 & $\begin{array}{l}\text { El espacio que ocupan los controles es adecuado al tamaño de la } \\
\text { pantalla }\end{array}$ & $\square$ & $\square$ & $\square$ & $\square$ & $\square$ \\
\hline & 7 & Los controles de navegación están visibles permanentemente & $\square$ & $\square$ & $\square$ & $\square$ & $\square$ \\
\hline & 8 & $\begin{array}{l}\text { Los botones de carácter icónico se utilizan para representar accesos } \\
\text { concretos }\end{array}$ & $\square$ & $\square$ & $\square$ & $\square$ & $\square$ \\
\hline & 9 & La descripción textual es adecuada y visible permanentemente & $\square$ & $\square$ & $\square$ & $\square$ & $\square$ \\
\hline & 10 & $\begin{array}{l}\text { El espacio que ocupan los controles es considerablemente inferior al } \\
\text { espacio que ocupan los contenidos }\end{array}$ & $\square$ & $\square$ & $\square$ & $\square$ & $\square$ \\
\hline
\end{tabular}

\begin{tabular}{|c|c|c|c|c|c|c|c|}
\hline : & 11 & $\begin{array}{l}\text { Los elementos de la interfaz se agrupan visualmente en relación con sus } \\
\text { funciones }\end{array}$ & $\square$ & $\square$ & $\square$ & $\square$ & $\square$ \\
\hline 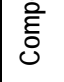 & 12 & $\begin{array}{l}\text { La posición de los elementos de la interfaz contribuye al equilibrio visual } \\
\text { de la composición }\end{array}$ & $\square$ & $\square$ & $\square$ & $\square$ & $\square$ \\
\hline
\end{tabular}

\begin{tabular}{|c|c|c|c|c|c|c|c|}
\hline \multirow{3}{*}{ 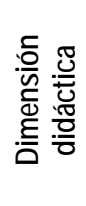 } & 13 & $\begin{array}{l}\text { La aplicación informática presenta unos contenidos informativos } \\
\text { suficientes y claros. }\end{array}$ & $\square$ & $\square$ & $\square$ & $\square$ & $\square$ \\
\hline & 14 & El desarrollo informático presenta imágenes de buena calidad técnica & $\square$ & $\square$ & $\square$ & $\square$ & $\square$ \\
\hline & 15 & $\begin{array}{l}\text { El procedimiento informático presenta información adicional a través de } \\
\text { enlaces a páqinas web y glosarios, que complementan la formación. }\end{array}$ & $\square$ & $\square$ & $\square$ & $\square$ & $\square$ \\
\hline
\end{tabular}

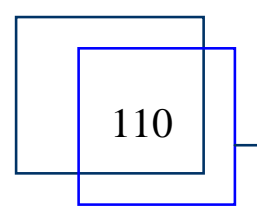

Juan Antonio Juanes Méndez, Alberto Prats Galindo y Juan José Gómez Borrallo 


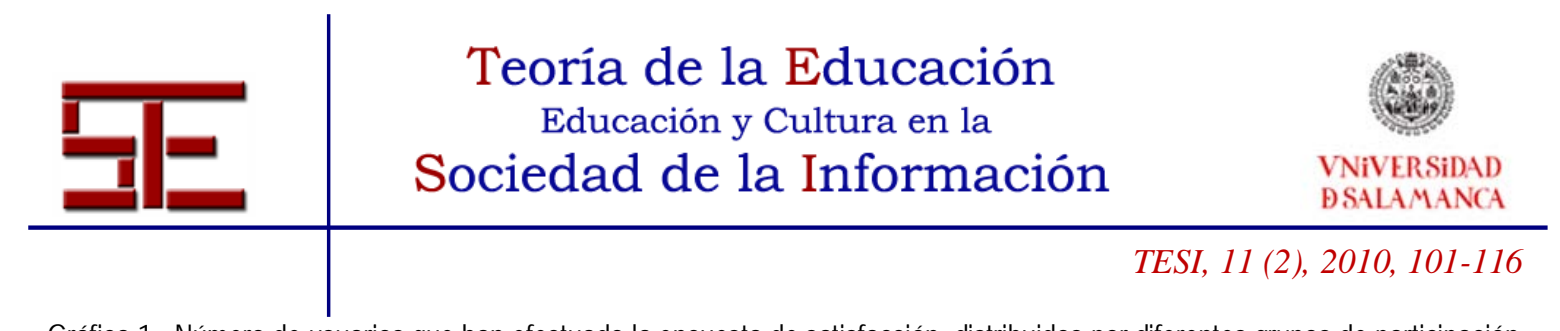

Gráfica 1.- Número de usuarios que han efectuado la encuesta de satisfacción, distribuidos por diferentes grupos de participación

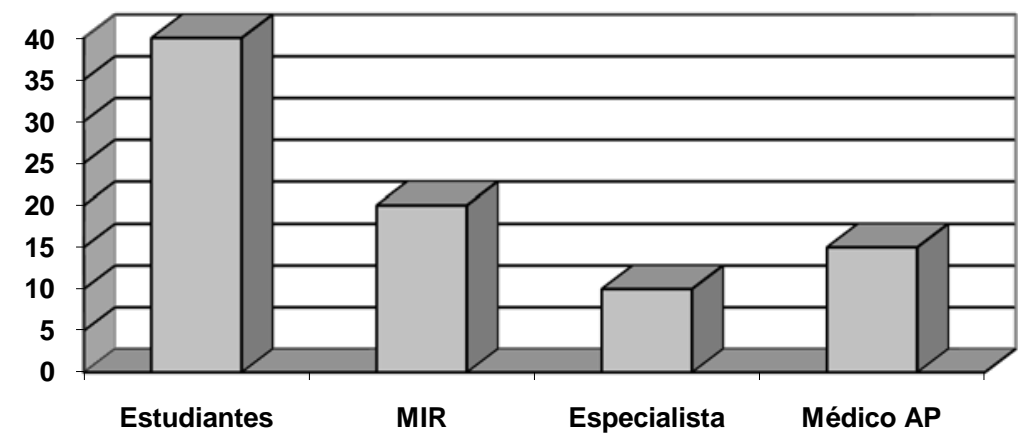

Gráfica 2.- Valores medios, usuarios: estudiantes n=40:

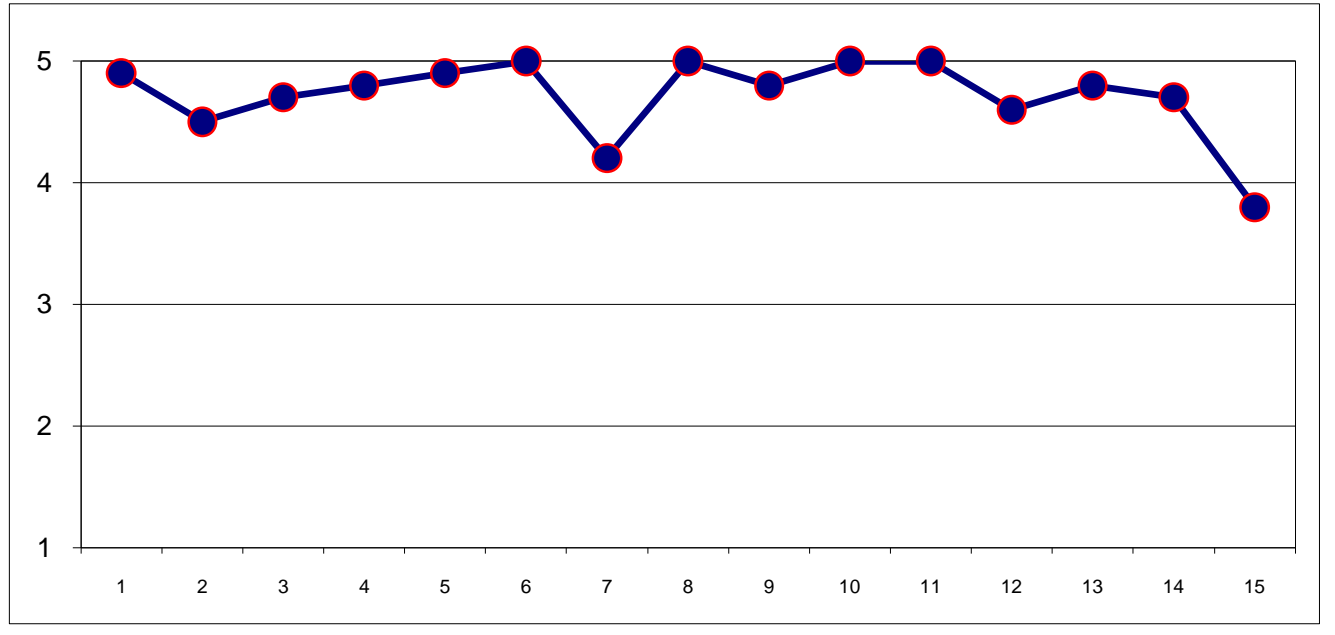

Gráfica 3.- Valores medios, usuarios: Médicos Internos Residentes (MIR): $n=20$

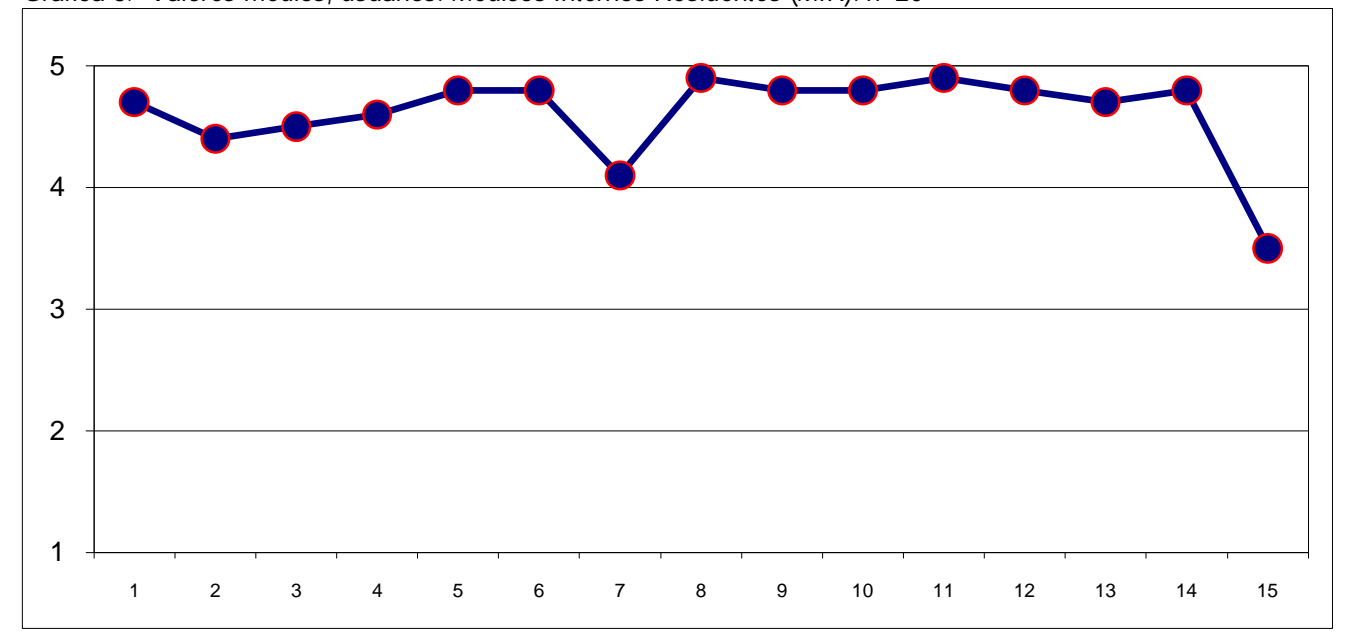

Juan Antonio Juanes Méndez, Alberto Prats Galindo y Juan

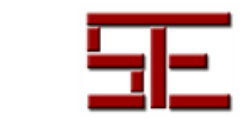
José Gómez Borrallo 
Teoria de la Educación

Educación y Cultura en la

Gráfica 4.- Valores medios, usuarios: Especialistas: $n=10$

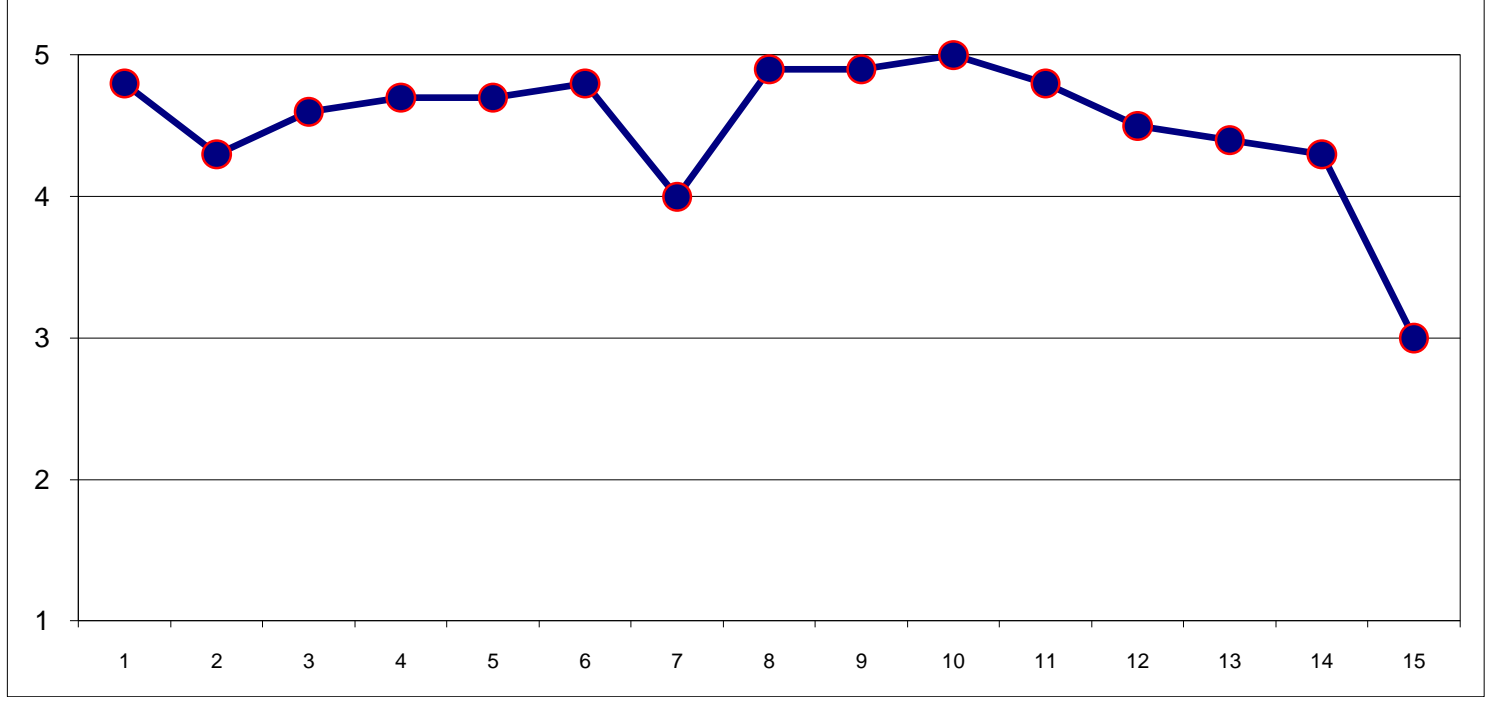

Gráfica 5.- Valores medios, usuarios: Médicos de Atención Primaria: n=15

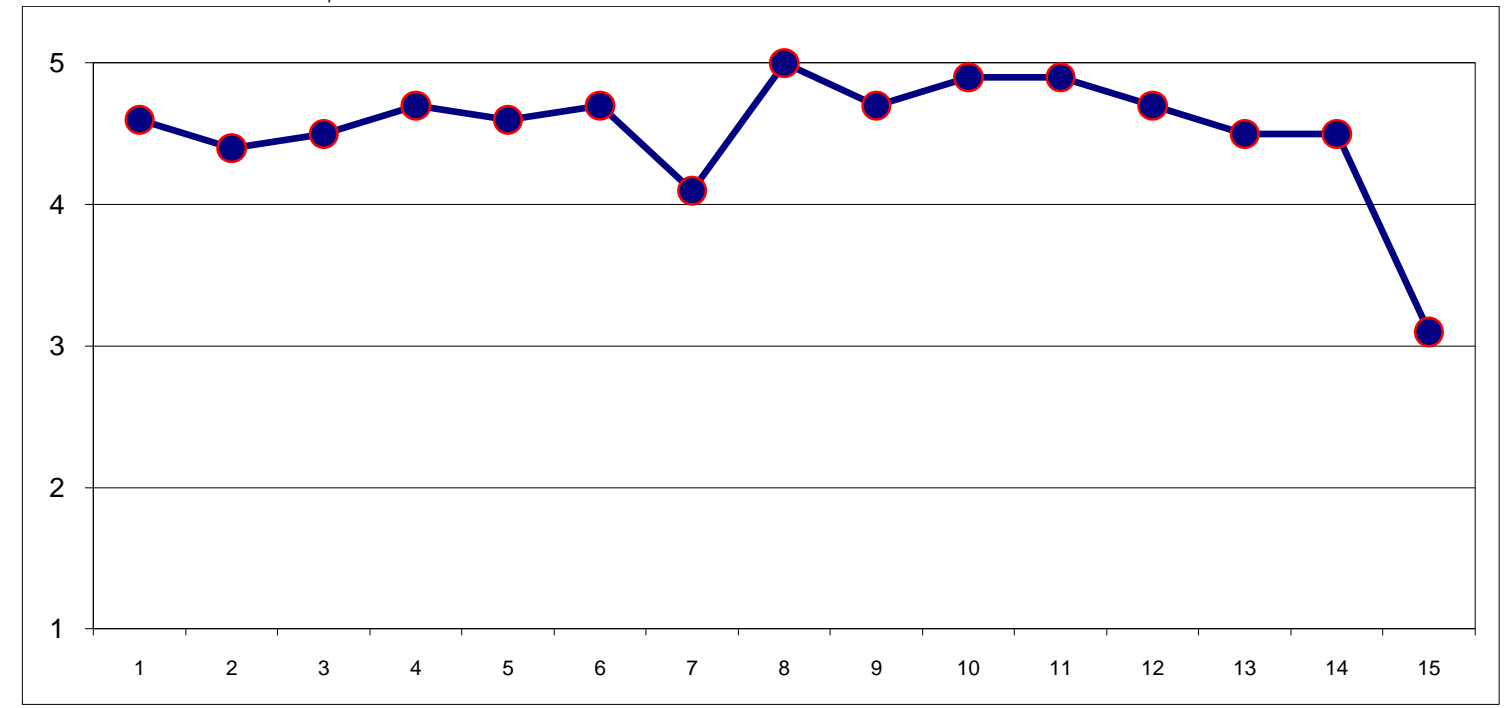




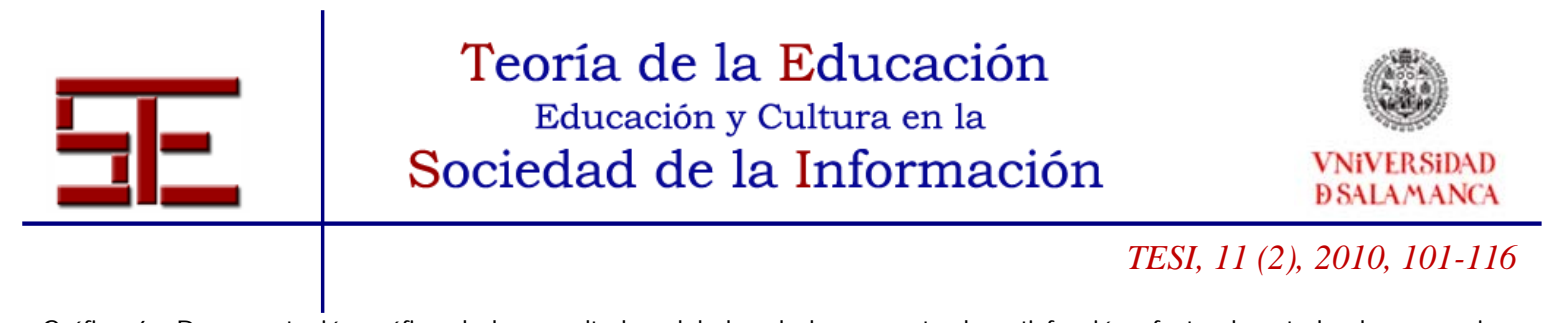

Gráfica 6.- Representación gráfica de los resultados globales de la encuesta de satisfacción efectuada a todos los usuarios. Destacan unos valores medios altos en todos los ítems formulados.

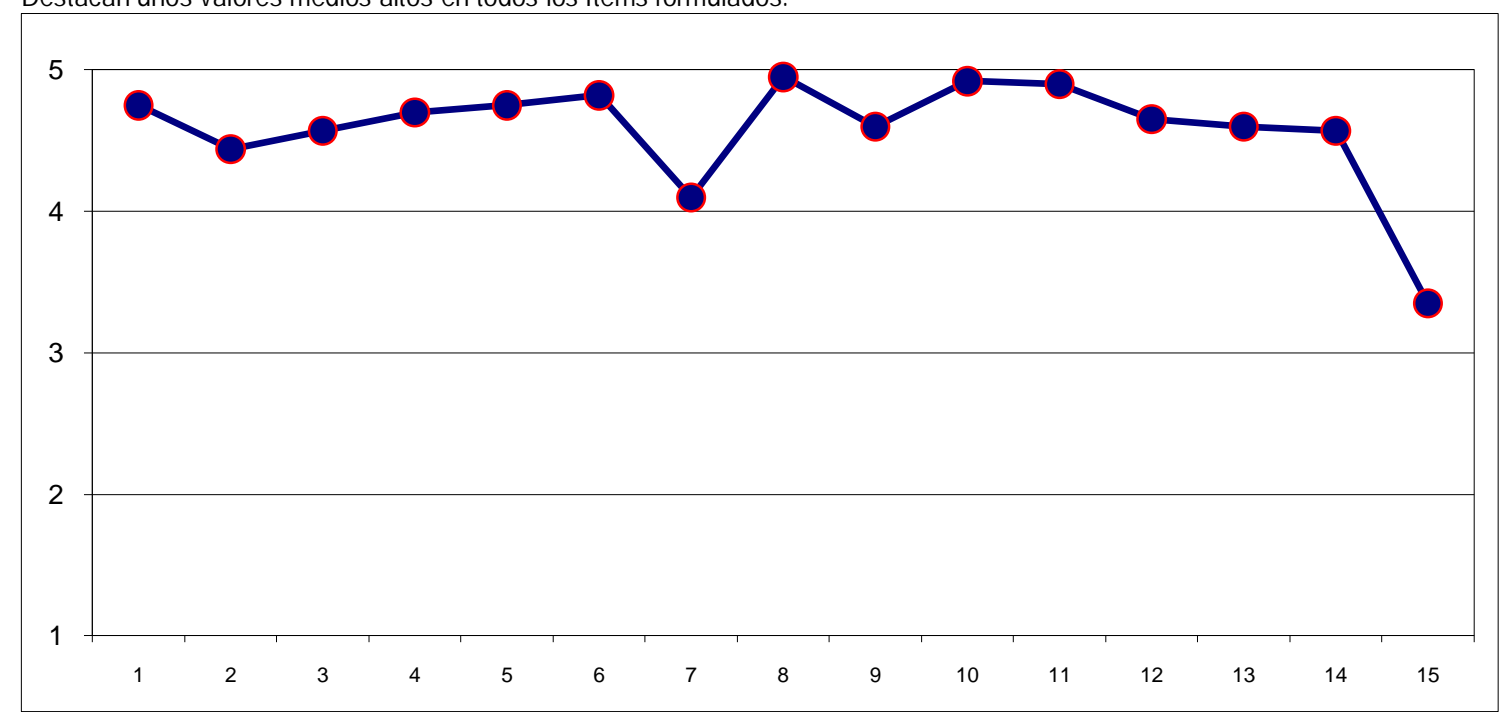

Tabla 1.- Resumen de los valores medios de los diferentes ítems formulados en la encuesta de satisfacción.

\begin{tabular}{c|cccc|} 
item & Estudiantes & MIR & Especialistas & Médicos AP \\
\hline 1 & 4,9 & 4,7 & 4,8 & 4,6 \\
2 & 4,5 & 4,4 & 4,3 & 4,4 \\
3 & 4,7 & 4,5 & 4,6 & 4,5 \\
4 & 4,8 & 4,6 & 4,7 & 4,7 \\
5 & 4,9 & 4,8 & 4,7 & 4,6 \\
6 & 5,0 & 4,8 & 4,8 & 4,7 \\
7 & 4,2 & 4,1 & 4,0 & 4,1 \\
8 & 5,0 & 4,9 & 4,9 & 5,0 \\
9 & 4,8 & 4,8 & 4,9 & 4,7 \\
10 & 5,0 & 4,8 & 5,0 & 4,9 \\
11 & 5,0 & 4,9 & 4,8 & 4,9 \\
12 & 4,6 & 4,8 & 4,5 & 4,7 \\
13 & 4,8 & 4,7 & 4,4 & 4,5 \\
14 & 4,7 & 4,8 & 4,3 & 4,5 \\
15 & 3,8 & 3,5 & 3,0 & 3,1 \\
\hline
\end{tabular}

Juan Antonio Juanes Méndez, Alberto Prats Galindo y Juan

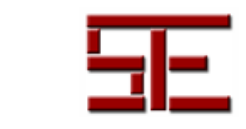
José Gómez Borrallo 


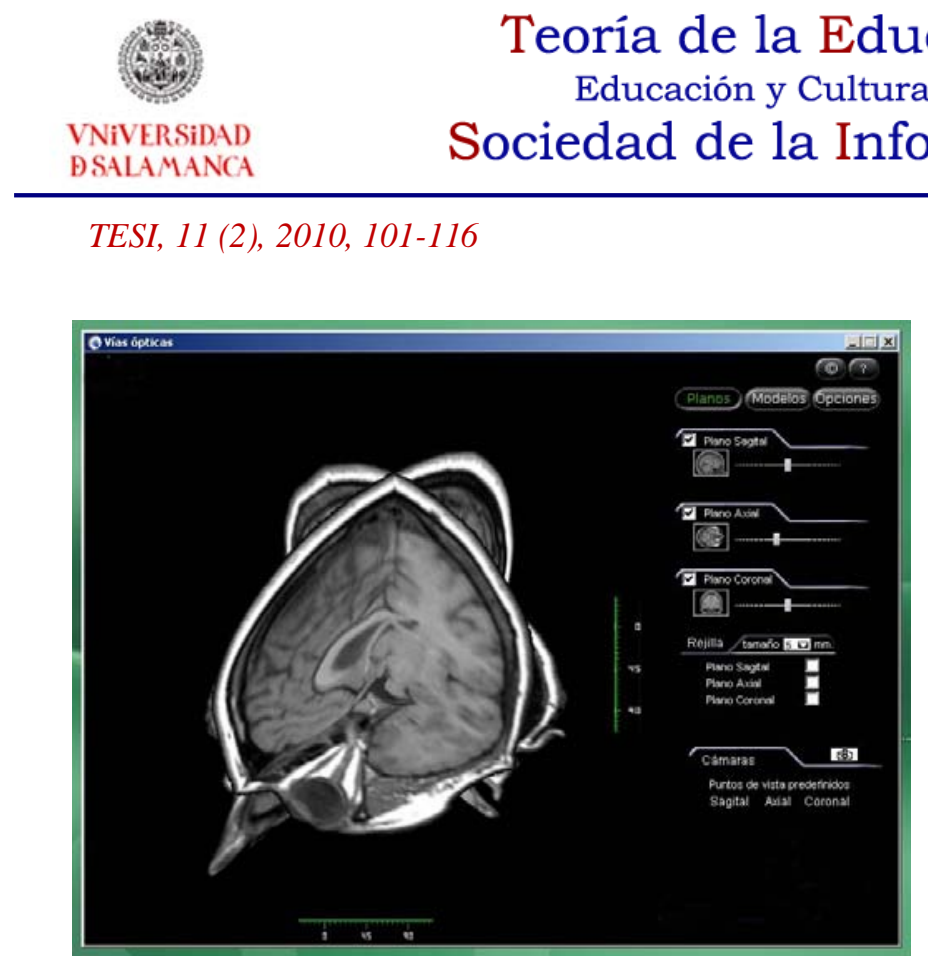

Figura 5. Panorámica general del interfaz de usuario y detalle del menú de opciones, donde se visualizan, mediante pequeños iconos de Resonancia Magnética, los distintos planos de sección que se pueden practicar, con barra de desplazamiento para la selección del corte requerido.

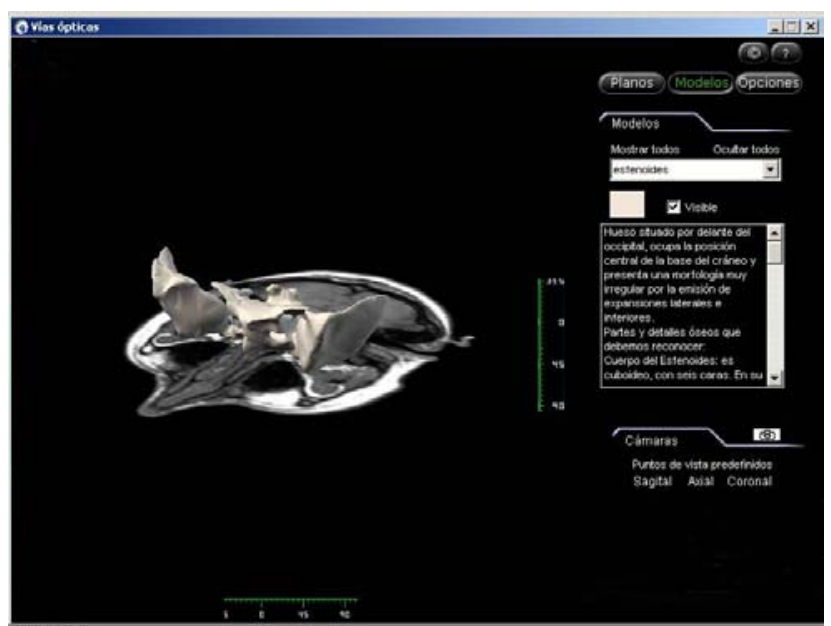

Figura 6. Visión general del interfaz de usuario y detalle del mismo, donde se aprecia un recuadro de texto que explica, de forma breve, la estructura tridimensional seleccionada. También se puede observar un pequeño icono de cámara para capturar y almacenar la imagen que se visualiza, así como los distintos puntos de vista en los que podemos verlo.
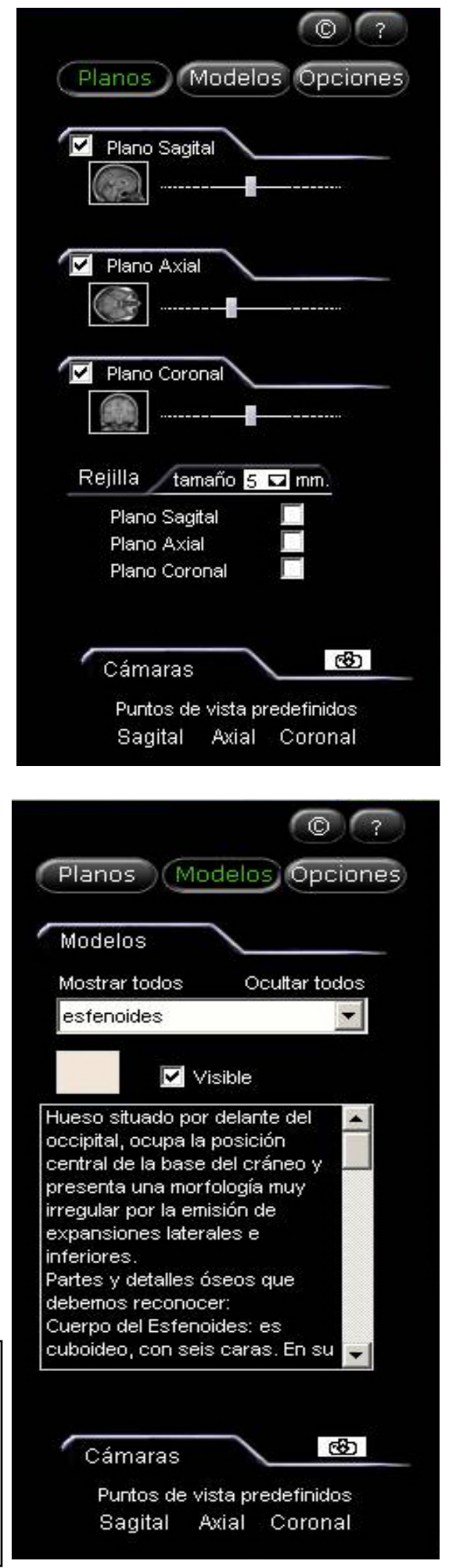

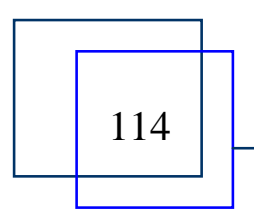

Juan Antonio Juanes Méndez, Alberto Prats Galindo y Juan José Gómez Borrallo

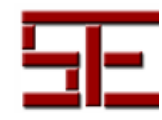




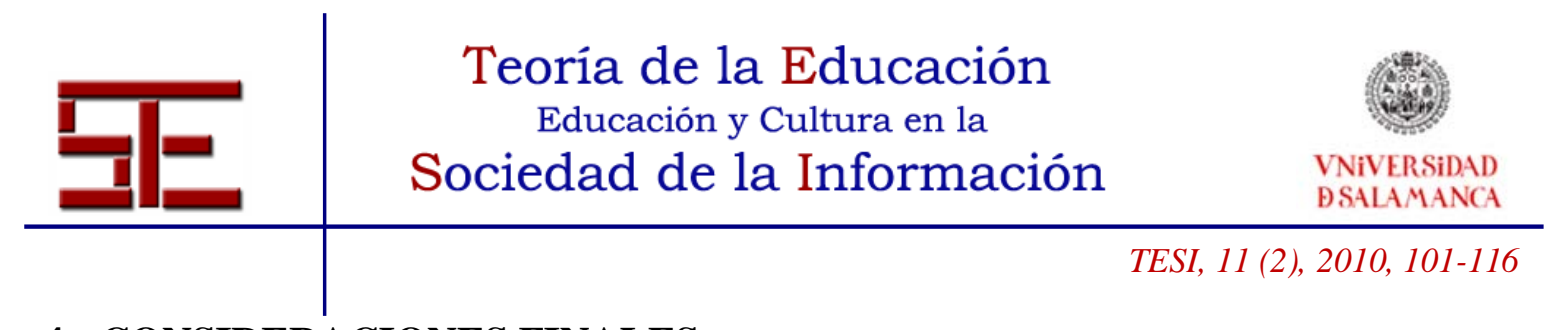

\section{4.- CONSIDERACIONES FINALES}

Está ya probado y por tanto, parece evidente, que la utilización de métodos informáticos en la enseñanza universitaria mejora en la consecución de los objetivos docentes. La innovación educativa es un proceso complejo en el que participan no solamente el profesorado sino también la propia institución; por eso tanto los profesores y las propias instituciones universitarias, han de adaptar los procesos de enseñanza-aprendizaje, con el objetivo de acentuar la implicación activa de nuestros estudiantes en su proceso de aprendizaje, para ello deberán introducir las herramientas tecnológicas que la sociedad actual impone y a la que los nuevos estudiantes están acostumbrados a manejar.

La utilización de programas docentes informatizados en la docencia supone una importante adecuación y análisis de los contenidos docentes a transmitir para que sean adquiridos por los alumnos, así como una cuidadosa presentación de los mismos, para que le mensaje y los conocimientos a transmitir lleguen al estudiante de la manera más eficaz. Por ello, es muy importante el diseño de la aplicación informática, para que resulte no solo atractiva para el usuario, sino para que el tiempo que emplee el alumno en su aprendizaje, sea optimizado y facilite los conocimientos.

Entre las características que contribuyen a construir un interface sencillo de utilizar y claro en sus contenidos, destaca la utilización de iconos ilustrativos que sirvan de ayuda y guía para simplificar al usuario la operación del sistema, y por tanto la interactividad con la aplicación informática.

La navegación por un programa docente informatizado debe ser reducida a la mínima expresión, permitiendo al usuario (alumno), sentir que se mantiene en un único desarrollo que solamente varía en función de su trabajo didáctico, sin tener que acudir a ayudas externas o adicionales; brindándole una sensación de autonomía.

Nuestra experiencia en los diseños de interfaces, en las aplicaciones informáticas docentes que hemos desarrollado, encontramos un alto grado de satisfacción por parte de los usuarios finales, manifestado en las encuestas practicadas. Posiblemente, la calidad, diseño y presentación de estos interfaces de usuario sea la causa del éxito de un procedimiento informático didáctico óptimo para la formación, además de los contenidos aportados.

Juan Antonio Juanes Méndez, Alberto Prats Galindo y Juan

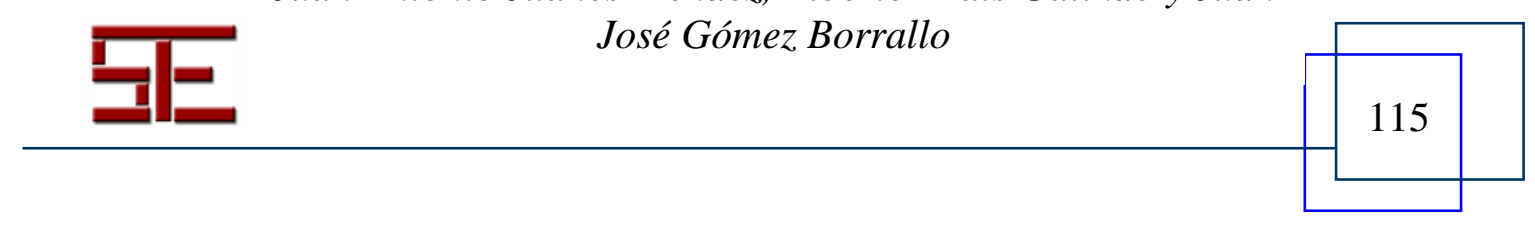




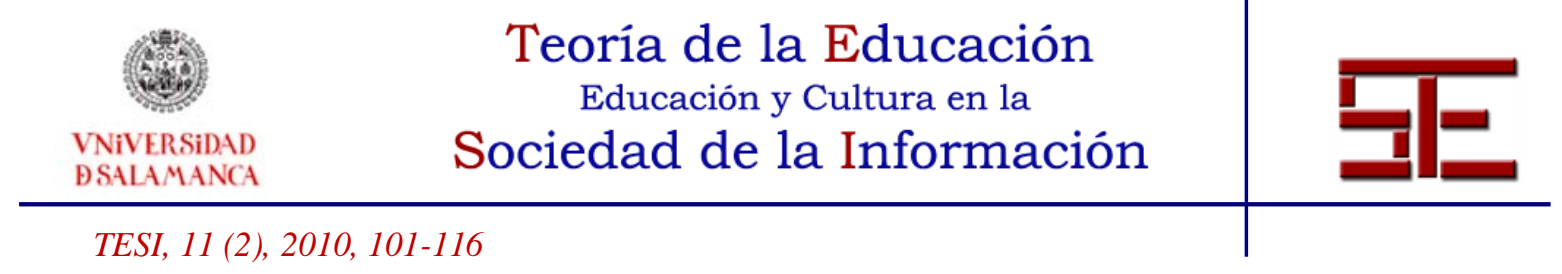

\section{5. - BIBLIOGRAFÍA.}

Benbasat, I., Y Todd, P. (1993): An experimental investigation of interface design alternatives: Icon vs. Text and direct manipulation vs. Menus, International Journal of Man-Machine Studies, Kellener \& Barnes

Espuña Pons, M.X., Juanes Méndez, J.A., Prats Galino, A., Tomás Batlle, J.J., Gómez Borrallo, J.J And Iglesias Guiu, X. (2006): Modelización virtual de la pelvis femenina a partir de imágenes de resonancia magnética. SueloPélvico, 2(3): 85-90.

Juanes, Ja., Espinel, J.L., Velasco, M.J., Zoreda, J.L., Riesco, J.M., Carmena, J.J., Blanco, E., Marcos, J. Y Vázquez, R. (1996): A Three-dimensional virtual model of the head generated from digitalized CT and MR images for anatomical-radiological and neurosurgical evaluations. J. of Neuroradiology (1996), 23:211-216.

Juanes, Ja., Prats A., Riesco, J.M., Blanco, E., Velasco, M.J., Cabrero, F.J. Y Vázquez, R. (2001). Computerized model for the integration of data associated with the human brain. Euopean Journal of Anatomy, (2001). 5: 133-138.

Juanes, J.A., Prats, A Y Gómez, J.J (2006). Desarrollo informático para la visualización gráfica tridimensional y el aprendizaje de la musculatura extrínseca del globo ocular. III Jornadas Internacionales de Innovación Universitaria. Universidad Europea de Madrid. Madrid. JIU. Ed. Calidad Educativa.

Likert, R. (1932): A Technique for the measumerement of attitudes. Archives of Psychology, 140, 1-55.

Mordecki, D. (2007). Interfaces e Intuición. Faz, Vol. 1, №1: 15-18.

Rogers, Y. (1989). Icons at the interface: their usefulness. Interacting with Computers, 1(1), 105-117.

Para citar el presente artículo puede utilizar la siguiente referencia:

Juanes Méndez, J.A., Prats Galindo, A y Gómez Borrallo, J. (2010): Avances en el desarrollo de interfaces de usuario de programas docentes: importancia de su diseño para la eficacia y optimización del aprendizaje, en Juanes Méndez, J. A. (Coord.) Avances tecnológicos digitales en metodologías de innovación docente en el campo de las Ciencias de la Salud en España. Revista Teoría de la Educación: Educación y Cultura en la Sociedad de la Información. Vol. 11, $\mathrm{n}^{\circ}$ 2. Universidad de Salamanca, pp. 101-116 [Fecha de consulta: dd/mm/aaaa]. http://campus.usal.es/ revistas_trabajo/index.php/revistatesi/article/view/7073/7106

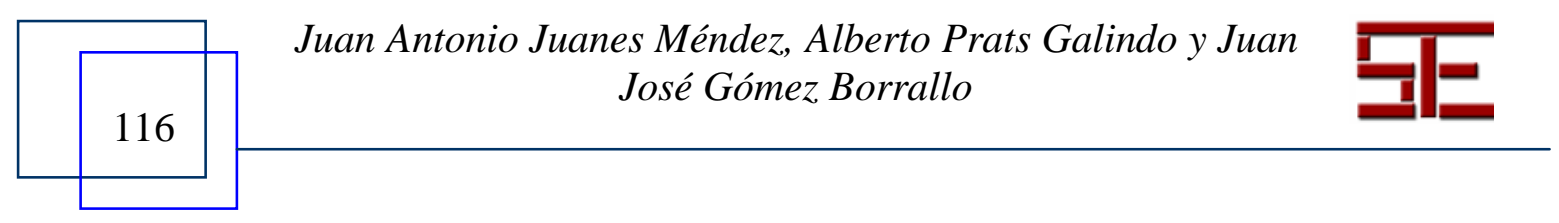

